\title{
PERFORMANCE OF PHYSIOLOGICAL BASIS OF RICE HYBRIDS UNDER SYSTEM OF RICE CULTIVATION
}

\author{
Pushrraj Singh ${ }^{1}$, IM Khan ${ }^{1}$, Smita Singh ${ }^{2 *}$, RK Tiwari ${ }^{1}$, \\ UN ShuKla $^{2}$ and PhiJi Philip ${ }^{1}$ \\ Department of Agronomy, Jawaharlal Nehru Krishi Vishwa Vidyalaya, \\ College of Agriculture, Rewa-468001, India
}

Key words: Performance, Physiological basis, Rice hybrids, Rice cultivation

\begin{abstract}
Among the rice hybrids, PRH-10 recorded significantly highest chlorophyll content, dry matter, LAI, CGR, RGR, NAR, root length, root: shoot ratio and grain yield (9.95 t/ha) over the rest of hybrids followed by NPH-567. The lowest values of these parameters were noted in IR-36. The higher straw yield was recorded (144.8 t/ha) in NPH-567.
\end{abstract}

Rice currently feeds more than half of the world's population, and demand for rice is expected to rise by almost $40 \%$ within 30 years due to population increase (Surridge 2004). The System of Rice Intensification (SRI), which was developed in Madagascar, has brought hope to many rice farmers as it claim to accomplish more rice per drop of water. It is a methodology for comprehensively managing resources, i.e. changing the way that land, seeds, water, nutrients and human labour are utilized. SRI is an amalgamation of multiple beneficial practices, being a lowcost, high-yielding system that could be a sustainable alternative to conventional paddy production. Many reports showed yield enhancement by $25-50 \%$ or more on the basis of field experiences or on-farm trials (Kabir and Uphoff 2007, Satyanarayana et al. 2007, Sinha and Talati 2007, Zhao et al. 2009).

The objective of the present study was to investigate whether variation in rice genotype on basis of canopy structure, growth parameters, chlorophyll index, dry matter accumulation, root growth and how different hybrid rice varieties might perform under System of Rice Intensification (SRI) management. These parameters, if properly measured and help to resolve some of the controversy surrounding SRI in the agronomic literature and could also contribute to improvements in rice culture.

The experimental material consisted of 11 hybrid rice (JRH-4, JRH-5, JRH-8, JRH-10, JRH11, PRH-10, NPH-207, NPH-567, NPH-4113, NPH-369, NPH-999) with IR -36 as a control and was grown in a randomized complete block design with four replications at the Research Farm, College of Agriculture, Rewa (Madhya Pradesh) during the rainy season of 2008-09. Fourteen day old seedlings were transplanted with spacing of $20 \mathrm{~cm} \times 20 \mathrm{~cm}$. The total rainfall received during the crop season was $672.6 \mathrm{~mm}$ distributed in 37 rainy days. The soil of the experimental site was clay-loam having favourable $\mathrm{pH}(7.1)$ and $\mathrm{EC}(0.31 \mathrm{ds} / \mathrm{m})$. The soil was medium in organic carbon $(0.61 \%)$, available $\mathrm{N}\left(270 \mathrm{~kg} / \mathrm{ha}\right.$ ) and high in $\mathrm{K}_{2} \mathrm{O}(353 \mathrm{~kg} / \mathrm{ha})$, but low in $\mathrm{P}_{2} \mathrm{O}_{5}(8.25 \mathrm{~kg} / \mathrm{ha})$. Periodical observations were recorded for growth analysis parameters and yield. Chlorophyll content of each randomly selected leaf of sampled plant was measured by the CCM-200 chlorophyll meter. The meter measures the absorbance of wave length and calculates as chlorophyll index and the root-shoot ratio of randomly selected plant of rice were calculated on

*Author for correspondence: <sapnapuat@gmail.com>. ${ }^{1}$ Jawaharlal Nehru Krishi Vishwa Vidyalaya, College of Agriculture, Rewa-468001, India. ${ }^{2}$ Department of Agronomy, Institute of Agricultural Sciences, BHU, Varanasi-221005, India. 


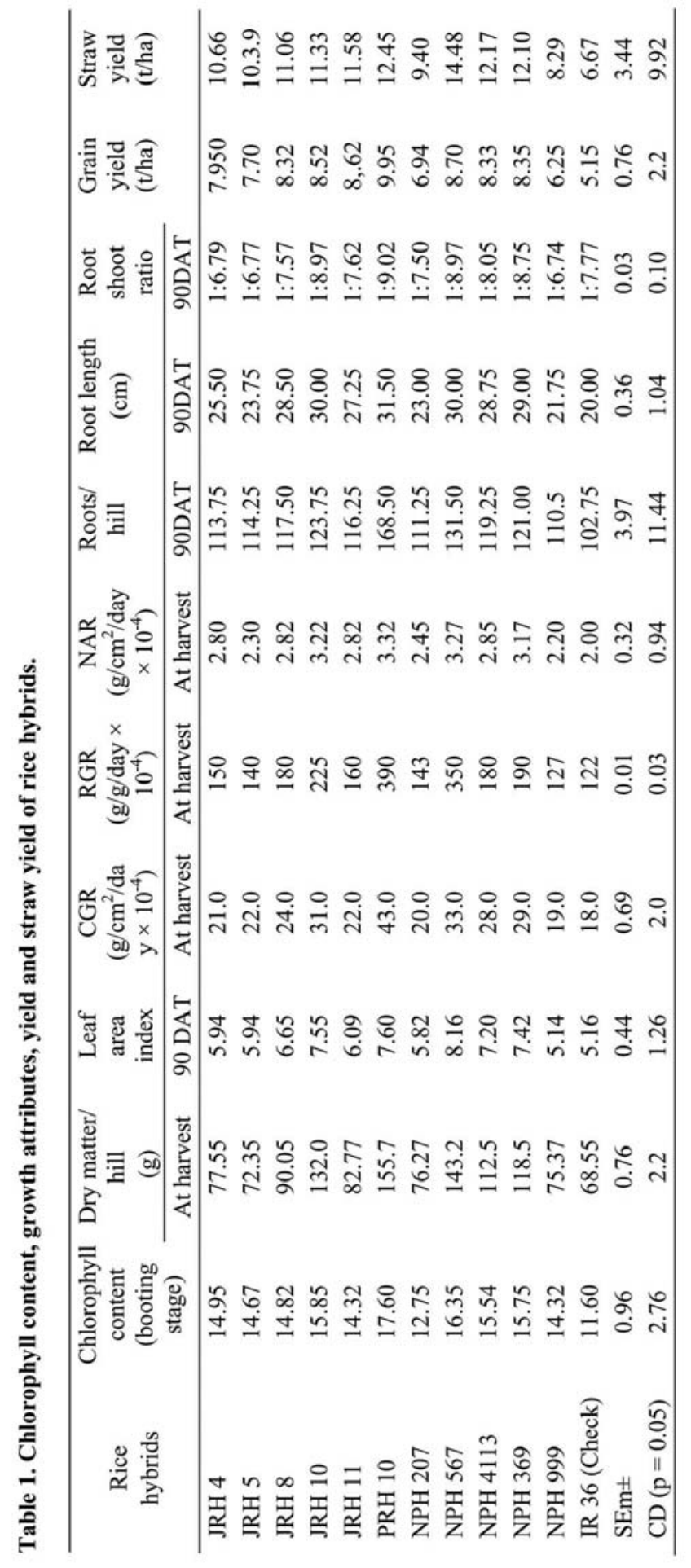


dry weight basis. Different growth and physiological parameters such as LAI, CGR, RGR and NAR, were calculated by following standard formulae of Radford (1967).

Amongst the rice hybrids, PRH-10 attained the higher chlorophyll content (17.60) at the booting stage and dry matter/hill (155.7g), followed by NPH-567 and JRH-10 (Table 1). This might be due to higher per unit uptake of fertilizer in these hybrids over the others. The leaf area index, crop growth rate, relative growth rate and net assimilation rate were also higher in PRH - 10 in the same order and lowest in IR-36. PRH - 10 showed higher metabolic potential and efficiency to exploit available resources (water and fertilizer) and also harness the solar energy as compared to other hybrids. PRH-10 recorded highest LAI which is correlated with photosynthesis and ultimately produced more dry matter per unit leaf area. At 90 DAT (days after transplanting) stage, PRH-10 recorded significantly longer root length $(31.5 \mathrm{~cm})$, root shoot ratio $(1: 9.02)$ then the remaining hybrids. (Table 1). These findings are in close agreement with those of Shivani and Reddy (2000) and Barisan (2002). The maximum productivity is the ultimate target of any crop producer. Due to maximum increase in all these growth parameters, PRH-10 hybrid produced the maximum grain yield $(9.95 \mathrm{t} / \mathrm{ha})$ which was higher by $4.80 \mathrm{t} / \mathrm{ha}$ as compared to IR-36 and significantly higher over rest of the rice hybrids. However, NPH-567 and JRH-10 stood the second and third best hybrids, respectively. Grain yield is the end result of all the vegetative and reproductive growth characters and genetic yield potential of PRH-10 which further to produce higher grain. Ajeet et al. (2005) also found similar results with respect to variation in the grain yield of hybrid rice and IR 36. Significantly higher straw yield (14.48 t/ha) was recorded by NPH567. Such an increase in straw yield of these rice hybrids might be due to the conversion of photosynthates into shoot as contrast to economic parts of the plant (Satyanaryan et al. 2007).

\section{References}

Ajeet, Singh R and KN Namdeo 2005. Performance of conventional and hybrid rice varieties under different fertility levels. Ann. Pl. Soil Res. 7(1): 91-92.

Barisan J 2002. Nutrient use efficiency and nutrient uptake in conventional and intensive (SRI) rice cultivation system in Madagascar. M.Sc. (Ag.) Thesis (Crop and Soil Science), Conrnell University, Ithaca, New York.

Kabir H and N Uphoff 2007. Results of disseminating the system of rice intensification with farmer field school methods in Northern Myanmar. Expl Agric. 43: 463-476.

Radford, P J 1967. Growth analysis formulae their use and abuse. Crop Sci. 7: 170 -175

Satyanarayana A, Thiyagarajan T M and N Uphoff 2007. Opportunities for water saving with higher yield from the system of rice intensification. Irrig. Sci. 25: 99-115.

Shivani D and N Sree Ram Reddy 2000. Correlation and path analysis in certain rice hybrids. Oryza 37(3): 183-186.

Sinha SK and J Talati 2007. Productivity impacts of the system of rice intensification: A case study in West Bengal, India. Agric Water Manage. 87: 55-60.

Surridge C 2004. Feast or famine. Nature 428: 360-361.

Zhao L, Wu L, Li Y, Lu X, Zhu D and N Uphoff 2009. Influence of the system of rice intensification on rice yield and nitrogen and water use efficiency with different $\mathrm{N}$ application rates. Expl. Agric. 45:275-286. 